\title{
A better life through diet and physical activity in the Nordic countries - how far have we come?
}

Since 2006 the Nordic countries have had the Nordic Plan of Action on diet and physical activity (HMM) as a common basis for work towards a healthier way of life for all. In all those 6 years the focus has very much been on responding to the challenges of inadequate physical activity, and the fact that our food intake does not live up to recommendations that ensure a healthy life and good lifestyle. The need for a broad-based approach to the area of health promotion and prevention is, however, still very relevant.

Targets 2011

- Intake of fruit and vegetables and wholegrain products to increase. Intake of fat, highly saturated fat and trans fats and added sugar to be reduced. Salt intake to fall or remain unchanged - depending on thenational context.

- The current trend, with a growing proportion of adults and children physically inactive, to be stopped or preferably reversed.

- The increase in the proportion of overweight and severely overweight citizens to have stopped or ideally declined.

- The existing divergences between social groups as regards unhealthy diet, physical inactivity and overweight not further increased, or reduced.

The action plan also contains some farther-reaching visions for 2021.
Since 2006 activities have been launched on several fronts - always with a view to using the potential and reaping the effects of Nordic cooperation. This Nordic cooperation is based on the many national initiatives in each of the Nordic countries.

Since the first progress report on HMM was drafted in 2009, some results are emerging from the initiatives launched over the years.

To get an impression of whether the initiatives launched are having any effect, one of the first priorities was to determine a method to monitor developments in the Nordic countries. In 2011, following thorough preparatory work, a base-point measurement was carried out. The next measurement will be carried out in 2013-14. From that, developments thereafter will be able to be monitored, and it will be possible thereby to get a better sense of whether meeting the targets is going in the right direction.
For the work to have the optimum effect the involvement of many stakeholders and sectors is required - and here it will be appropriate to make particular use of public-private partnerships. Thus the progress report also includes examples of some successful initiatives within this area.

This progress report, 6 years after the action plan was decided upon, will give a picture of the principal activities at the Nordic and national levels.

It appears that there is still a long way to go to meeting the targets set for 2011, and the visions set for 2021. Therefore it will also be interesting to see what initiatives are launched in the forthcoming period. Nordic Plan of Action on diet an physical activity: http://www.norden.org/da/ publikationer/publikationer/2006-746 


\section{NNR - What should we be eating?}

In 2008 work began on a new version of the Nordic Nutrition Recommendations www.nnr5.org, to be launched in $2012 / 2013$. The new version will, among other things, include a review and update of e.g. types and amounts of fat and carbohydrates, food-based recommendations and how to integrate physical activity. Dietary conditions for specific target groups, e.g. the overweight, children, pregnant and breast-feeding women and the elderly will be examined in particular. Moreover, the need to take account of new issues, e.g. environmental aspects, will be assessed. The work will be open and will apply established methods of evidence grading.

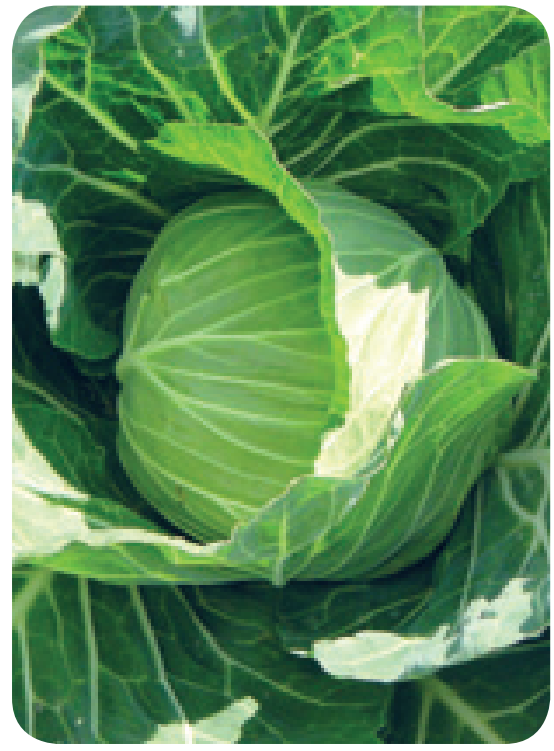

The practical work

The review work will be led by a project group appointed by the Nordic Council of Ministers, which has the main responsibility for the work and for the drafting of the final proposal. The review of selected chapters and new areas will be conducted by selected experts and expert groups. The evaluation of the scientific evidence grade, the study quality etc. will be carried out applying established guidelines and criteria in established systems. The work will take note of international activities within the area. The scientific bases will be evaluated by other experts via specialist evaluations. The project group, in conjunction with the project steering committee and a scientific reference group attached to the project, is responsible for the final drafting of the recommendations, and will compile a proposal for the new version. The proposal will be presented

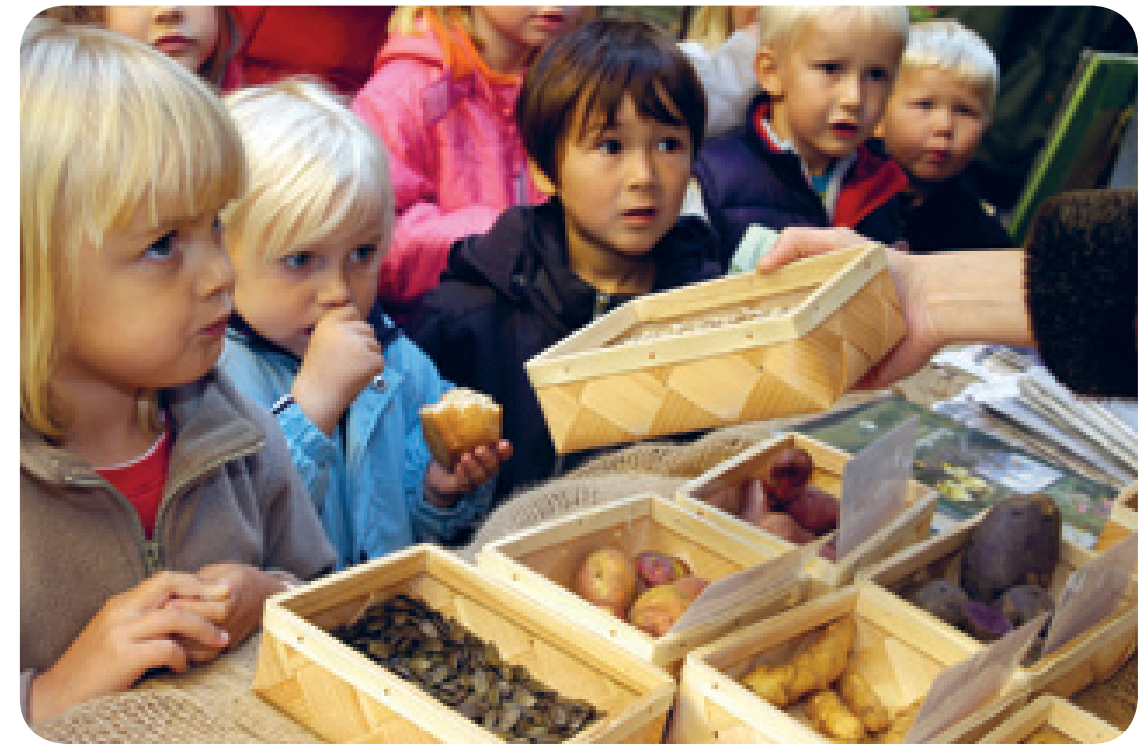

at the 10th Nordic Nutrition Conference, Reykjavik in June 2012. After the conference, rounds of hearings will be conducted and hearings with a view to gathering views from national expert groups, professional organisations, authorities, universities, the food sector, consumer organisations etc. The project group will then draw up a final proposal, which will be sent to the Nordic Council of Ministers for formal approval.
Facts
The Nordic Nutrition Recommendations (NNR) have constituted an important basis for work on diet and nutrition issues in the Nordic countries since the first version in 1980 . They have been revised at 8-year intervals - and since publication the 2004 edition has topped the list of publication searches on the Nordic Council of Ministers website. This says something about how widely used they are, and that the NNR enjoy a high status within various sectors. One of the strengths of the NNR is that a single set of recommendations provides an integrated and concise group of recommendations for different nutrients and physical activity, the meaning of various groups of foodstuffs and meal patterns as well as the scientific background to the recommendations. 


\title{
The Nordic Keyhole: healthy choices made easy
}

\author{
The aim of the Keyhole is to make it easier for consum- \\ ers to choose healthier foods and to encourage manu- \\ facturers to develop healthier food products and to \\ reformulate existing products.
}

The voluntary label certifies that products, within 25 specific product groups, meet certain requirements for salt, sugar, fat and fibre content. Sweden, Norway and Denmark have developed the food groups based on the Nordic Nutrition Recommendations and are working actively to promote awareness and knowledge about the Keyhole among consumers, retailers and food producers, as well as relevant partners such as consumer and trade associations, wholesalers, food professionals and local authorities.

The Keyhole has very quickly become well known and accepted within the population in all three countries. There are more than 2000 branded products in Sweden and at least 1000 products in Denmark and Norway. Brand results for consumer awareness, knowledge and behaviour conducted in surveys in the three countries will be presented at the 10th Nordic Nutrition Conference.

Cooperation on the Nordic Keyhole has resulted in many synergies and activities within the fields of communication and legislation. Awareness is high. The prospects for future Keyhole tasks therefore seem very positive - and many interesting challenges still lie ahead.

Instead of the Keyhole, Finland has a heart symbol which has been awarded to

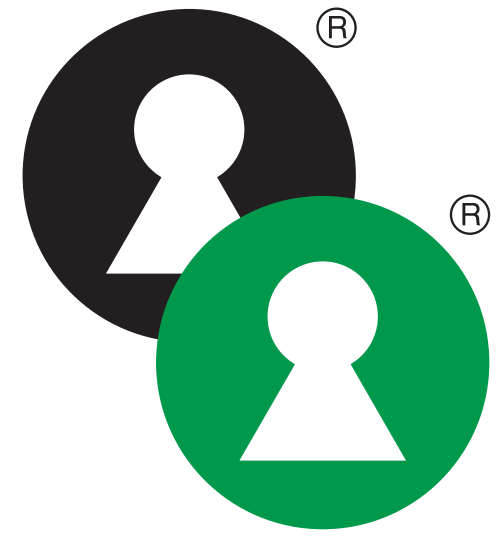

over 900 foods already. The foods need to meet requirements based on fat (fat type), salt, sugar, fibre and cholesterol. The heart symbol can also be given to meals in catering establishments.

Facts

Since 2007, Denmark, Norway and Sweden have been working together to launch and implement the Swedish-registered food label, the Keyhole. Denmark and Norway launched the Keyhole in June 2009.

\section{"Physical activity on prescription in the Nordic region - experiences and recommendations"}

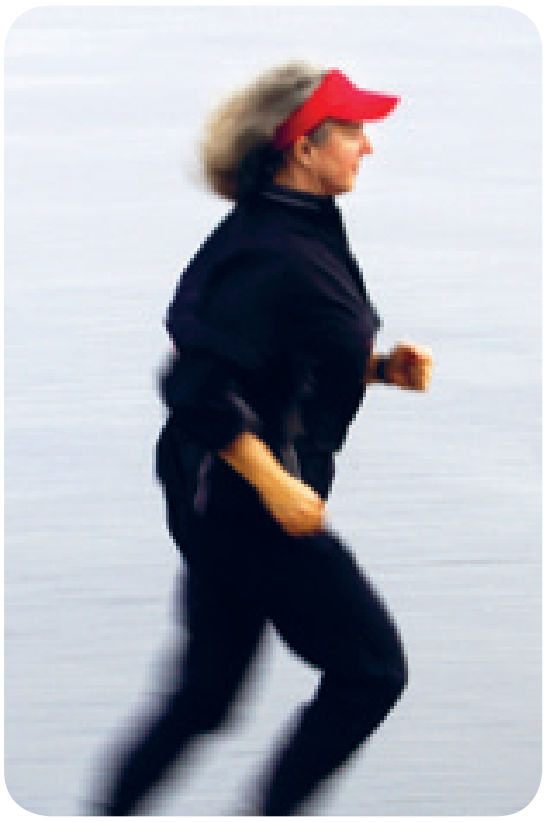

This project is being conducted on behalf of the "Nordic network for physical activity, food and health". One objective is to increase acceptance of physical activity on prescription in the health profession and on the political level, as well as to maintain its use and refine methods for physical activity on prescription.

In Denmark, Finland, Norway and Sweden, various models for prescribing physical activity through the healthcare services have been developed in the past decade. The objective of the report is to describe these different models. By summarising experiences and ana- lysing the advantages and disadvantages of the various models, recommendations can be made for future efforts in the Nordic region - identifying a Nordic "best practice" for the written prescription of physical activity with the possibility of local adaptation. It is important that both 
the activity prescribed and the support provided to cover the patient's needs is adapted to the individual.

In general, healthcare personnel should use two levels of efforts for patients who need to increase their physical activity for preventive or curative purposes. Patients are mainly offered motivational interviews with an individually adapted, written prescription of physical activity for the patient to conduct on his or her own (daily activity and/or organised activity). Patients who need more help to get started with physical activity are offered exercise groups within the healthcare services as an initial step. An individually adapted, written prescription can then facilitate the transition from structured exercise within the healthcare services to the individual becoming lastingly and independently physically active. However, it is not possible to propose a single model for physical activity on prescription in the Nordic region that suits all patients, prescribers and different local conditions. Work must therefore be adapted based on the prevailing circumstances.

\section{0th Nordic Nutrition Conference 2012 - Reykjavik, Iceland}

\section{The aim is to make the 10th Nordic Nutrition}

Conference on 3-5 June 2012 in Reykjavik a success. A particular objective of the conference is to create better understanding of the association between food, dietary habits and health with a particular focus on the new Nordic Nutrition Recommendations, food-based guidelines and nutrition policy.

The topics of the Nordic Nutrition Conference 2012 are:

\begin{tabular}{l|l}
\hline Nutrition recommendations & Food-based dietary guidelines \\
\hline Policy and public health interventions & Obesity in the Nordic countries \\
\hline System biology in nutrition & Nordic food and health \\
\hline Nutrition for vulnerable groups & Methodology in nutrition research \\
\hline
\end{tabular}

The conference committee comprises several nutritional experts from each of the five Nordic countries, 200 abstracts have been received and 400 registrations are expected.

A number of interesting presentations are planned. The programme starts on Sunday 3 June with several Nordic projects in parallel sessions, such as Nordic Monitoring on diet, physical activity and overweight. On Sunday afternoon a session is planned on the Nordic Diet Tradition and Health including presentations from Nord-Forsk supported by the
Nordic Centres of Excellence in food, nutrition and health. There will also be other presentations on co-Nordic projects such as the Keyhole. A progress report on the Nordic Plan of Action on better health and quality of life through diet and physical activity will also be presented. There will be sessions on e.g. obesity and vitamin D. On Tuesday morning, 5 June, a specific session is planned on the Nordic Nutrition Recommendations 2012. There will also be presentations on e.g. environmental sustainability and local food and on food and nutrition security, and on public health.
Facts

This Nordic network is based on cooperation between the Norwegian Directorate of Health, the Danish National Board of Health and the Swedish National Institute of Public Health and others. Today, besides Denmark, Norway and Sweden, Finland is also represented. The network receives financial support from the Nordic Council of Ministers and the secretariat of the network is the Nordic School of Public Health (NHV).

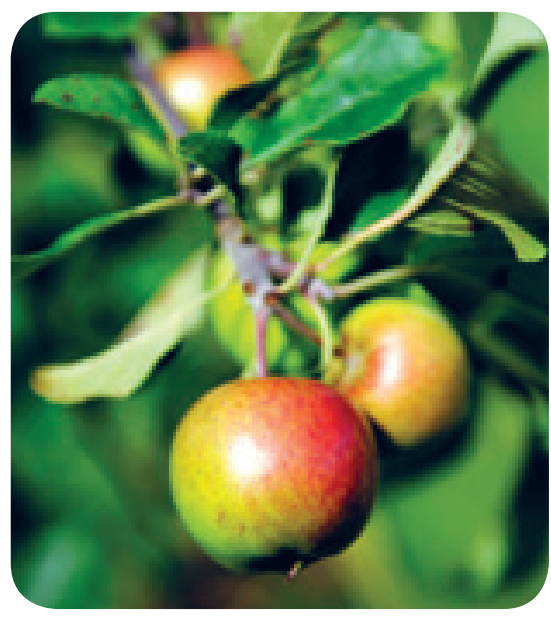

The Nordic Nutrition Conference meets the strategic principles of the Nordic countries within the food and health sector. It focuses on vital health issues, it promotes collaboration between industry, consumers and government institutions, it builds, uses and distributes knowledge and makes optimal use of resources in a prioritised field. It helps to prepare Nordic scientists for participating and taking a lead in international science and developmental projects in the field of nutrition and food and thereby increases their influence internationally.

The NNC 2012 will strengthen Nordic collaboration. The conferences have been of major importance for the development of official nutrition recommendations and public health for people in all age groups in the Nordic countries. The NNC is associated with the scientific nutrition societies, and those are associated with the FENS (Federation of European Nutrition Societies), which in turn are involved in the IUNS (International Union of Nutrition Sciences). 


\section{The Nordic website for children - with a new focus on diet and physical activity.}

\section{In summer $2012 \mathrm{dr} . \mathrm{dk} /$ norden will be expanded with a new content area focusing on Nordic food and the body's need for exercise. Like the rest of the site, the material is directed at approx. 10-14 year-olds, and the goal is to put the link between food, physical exercise and well- being on the agenda.}

The ambition of the new topic is to make children interested in investigating food culture and raw materials in their everyday - and to get children to look at their own lifestyle and learn about healthy alternatives. The material is accessed in a playful way. There will be a focus on digital activities such as games, quizzes and apps. Children will be able to learn through play rather than learn through reading.

The production team behind the website is working on three topics, which are expanded on below:

- Nordic food culture before and now

- From field to fork

- Your choice

\section{Nordic food culture} - before and now

The goal is for Nordic children to know the food culture of their own country and the Nordic food culture and have an understanding of the development of food culture in a historical perspective.

Possible approaches to the topic:

- Material on historical food preparation, e.g. the development of food in the Nordic region

- What the climate means for diet (e.g. particular raw materials)

- Technology in food preparation (minced meat dishes, pureed food etc.)

- Intake of food and calories compared with the activity level over the ages.

The topic can be presented through timelines, quizzes or similar.

\section{From Farm to Fork}

Nordic children can learn about a selection of particular Nordic raw materials and the conditions for growing food.

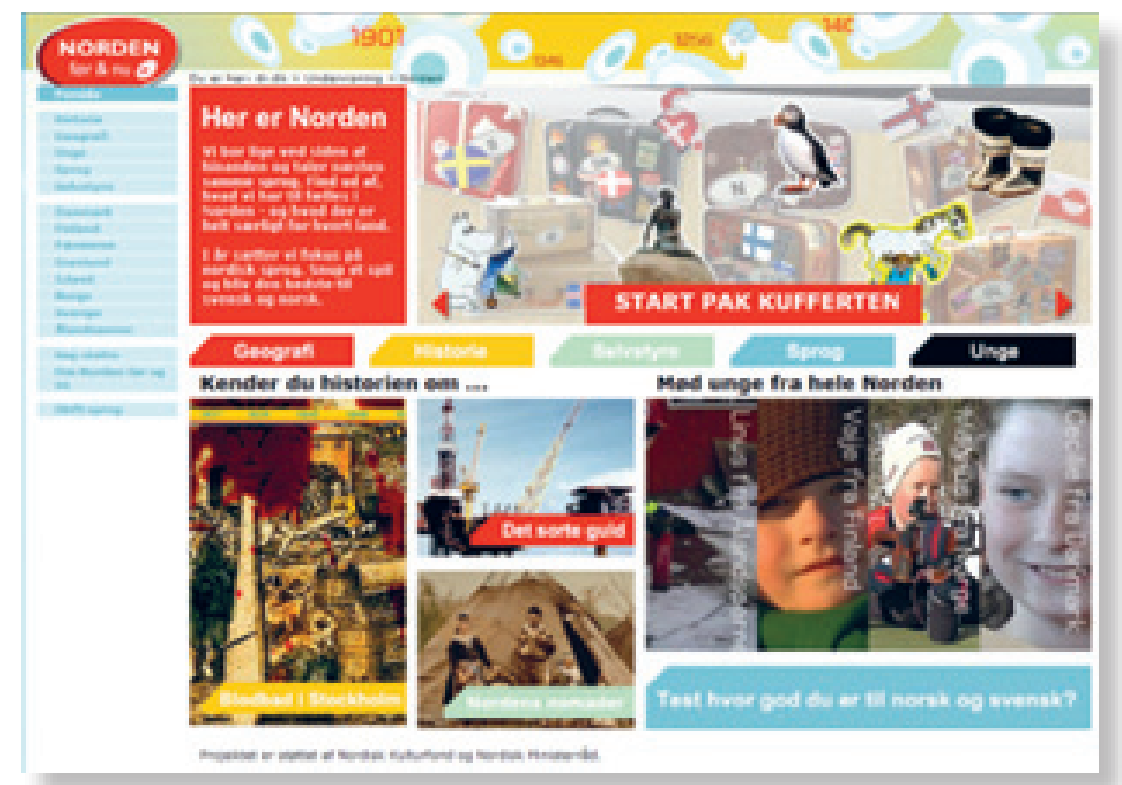

Facts

The website www.dr.dk/norden provides web-based education material for use by all Nordic school children. Here pupils and teachers can find ideas for classes of approx. 10-14 year-olds and learn about the Nordic countries, their shared history, geography, and not least the Nordic languages. Children can discover loads of TV clips, cartoon series, short articles, timelines, quizzes and games. The material, which is freely available for all, is provided by DR with support from the Nordic Council of Ministers and is in Norwegian, Swedish, Finnish, Icelandic and Danish.

The provisional ideas cover areas including:

- Material in From Farm to Fork will focus on exercises and learning about "Find the raw material", and how the earth and climate provide different cultivation possibilities.

- Possibly the ability to collect foods from the various Nordic countries on a virtual map, and e.g. allow pupils to see what grows naturally in the region. Pupils can also get a recipe task, where they can find the various ingredients in different countries.

\section{Your Choice}

The idea in this topic is to give children an understanding of how nutrition and health are interlinked. It is important that the information is communicated without a wagging finger, and that no pupils feel singled out for being wrong. The topic will focus on teaching pupils to make their own choice of "lifestyle" and make them understand that different activities call for a different energy intake. 
- One idea is "Fill up the tank", where you have to make choices all the time which are connected to your physical activity. Starting with a pre-determined calorie consump- tion pupils have to choose what foods he/she will eat in various situations: e.g. for an exam, for biathlon, as a snack, before hard physical work, a Sunday afternoon in front of the TV, before football

etc.

- The material can be developed as an app or a web game.

\section{Focus on timely intervention - Globalisation initiative welfare and health}

\section{In a unique way the Globalisation Initiative Welfare and Health brings together stakeholders from}

across the Nordic region, sectors and professions. In all, six Councils of Ministers are involved in the globalisation work: the Councils of Ministers for Working Life, Business, Energy \& Regional Policy, Fisheries and Aquaculture, Agriculture, Food and Forestry, Gender Equality, Health and Social Affairs, and Education \& Research. The individual sectors and subject areas complement each other and contribute their expertise to the project work.

Facts

On the Globalisation Initiative Welfare and Health:

The world is becoming increasingly globalised. Developments are moving faster and creating great challenges for the Nordic countries' competitiveness and welfare societies. But this development also brings with it great opportunities, if the countries are able to tackle the challenges wisely, and adapt and adjust in time. With a long tradition of cooperation, the Nordic countries can achieve more by coordinating and integrating their efforts rather than tackling the challenges alone. With this in mind, the Nordic prime ministers launched the Globalisation Initiative in 2009. Through closer Nordic cooperation the countries should develop effective solutions in areas including health and welfare.
The initiative is built around key topics: "Welfare-development in general and development of skills in the workforce, as well as inclusion" and "Health - promote a healthy, able-bodied population and quality of life". Seven independent sub-projects are listed under the two key topics. The initiative is based around the fact that welfare and health go hand in hand. A healthy population plays a major role in achieving competitiveness and growth. More information: http://www.norden.org/en/ nordic-council-of-ministers/ globalisation-co-operation/ concrete-globalisation-initiatives/ globaliseringsinitiativet-indenforvelfaerd-og-sundhed

The dominant practice hitherto has been to treat health-related problems as they arise. But current thinking in the welfare model, moving from a treatment society with costly short-term solutions to a prevention society with sustainable solutions, will bring down the financial costs and waste of human resources. At the same time the question arises: how can the Nordic countries strengthen
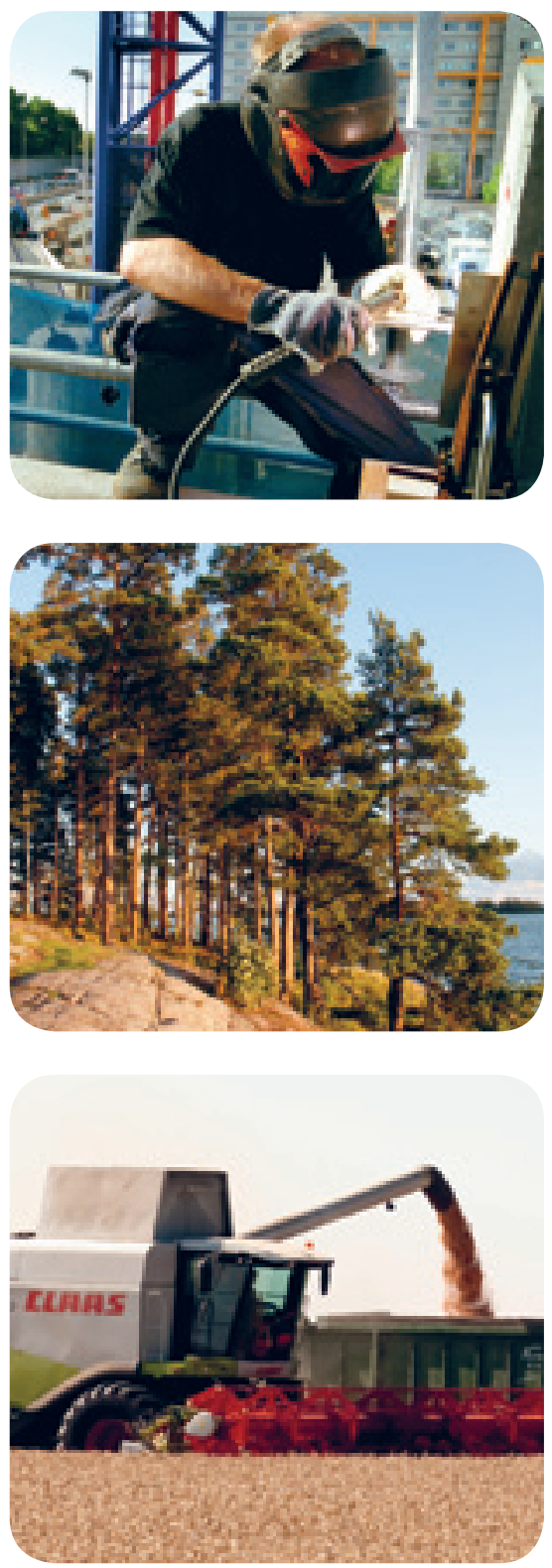

their prevention efforts effectively and intelligently within the social and health sector, including acting to halt the growth in chronic diseases. Three sub-projects within the Globalisation Initiative Welfare and Health focus on precisely this area. These are the subprojects on the topic: "Health - promote a healthy, able-bodied population and quality of life". 


\section{Health promotion and prevention}

Recent research suggests that lifestyle illnesses are affecting ever younger people. Therefore it is important to make parents aware of risk factors and especially what promotes their children's health. That is the basis for the project "Health promotion and prevention”.

There is broad agreement among those close to young people that this action should be taken when children are at pre-school age. That way, a healthy lifestyle becomes an integral part of young people's everyday life. The pro- ject "Health promotion and prevention" aims to help parents to develop and strengthen their preventive skills. For that, the group behind the project is developing a model for health-promoting dialogue between parents, specialists and researchers:

http://www.norden.org/da/nordiskministerraad/globaliseringssamarbejde/ konkrete-globaliseringsinitiativer/ globaliseringsinitiativet-indenforvelfaerd-og-sundhed/delprojekt-4sundhedsfremme-og-foerebyggelse

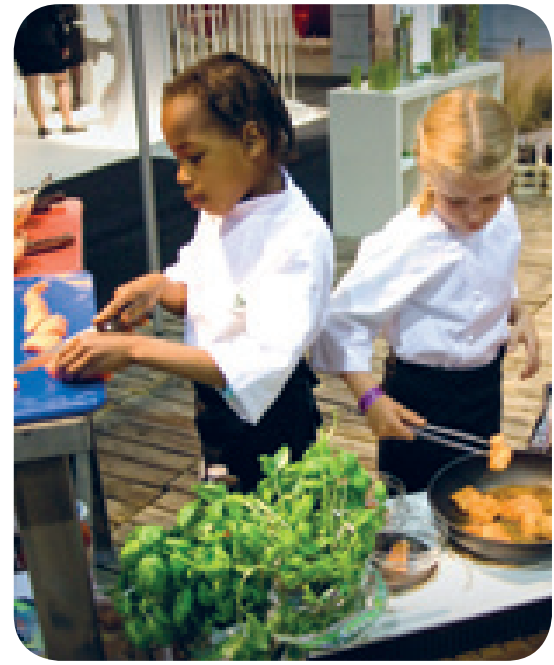

\section{Joint Nordic study of diet and physical activity started}

\section{Studies show that the Nordic region lacks a simple meth- odology for joint Nordic monitoring of diet and physical activity. Existing questionnaires are difficult to use and the results hard to compare. The project "Effects of action on prevention of lifestyle illnesses" aims to develop a joint Nordic monitoring system to measure trends in dietary habits, the level of physical activity, overweight as well as alcohol and smoking amongst the Nordic population.}

Against the background of the data gathered the project will result in a survey of diet and activity habits in various groups of the population. The questions need to provide answers as to whether the participants eat in line with the diet advice and how large a proportion meet the recommendations on physical activity. The intention is to be able to monitor changes in dietary habits, physical activity and overweight across the Nordic countries. The first study was carried out in autumn 2011 and will be followed up by a study in 2013/14.

A simple system for studying this using telephone interviews has previously been developed and validated, and now the first study has been carried out, and the first data on how often the Nordic population eats foods such as bread, vegetables, fruit, fat, sweets etc. has been collated.

In the 5 Nordic countries- Sweden, Norway, Finland, Iceland and Denmark - a total of over 9000 adults and approx. 2500 children have been asked a series of simple questions about how often they eat a number of foods, how often they exercise and a number of background questions e.g. about their height and weight.

With this background information it is also possible to compare men and women, children and adults, partici- pants with long and short education and not least what the situation is across the region in each Nordic country.

By repeating the study it will also be possible to show the trend in dietary habits and the level of physical activity, and thereby whether the trend is going in the right direction in all areas. The results may assist decision-making in launching, for instance, preventative activities at both the Nordic and national levels. The research method is very simple, however, and cannot replace other more thorough studies of diet and physical activity. The results of the study will be presented at the Nordic Nutrition Conference in Iceland in June 2012.

http://www.norden.org/da/nordiskministerraad/globaliseringssamarbejde/ konkrete-globaliseringsinitiativer/ globaliseringsinitiativet-indenforvelfaerd-og-sundhed/delprojekt-5effekter-af-indsatser-for-forebyggelse-aflivsstilssygdomme 


\section{Nutrition, learning and health}

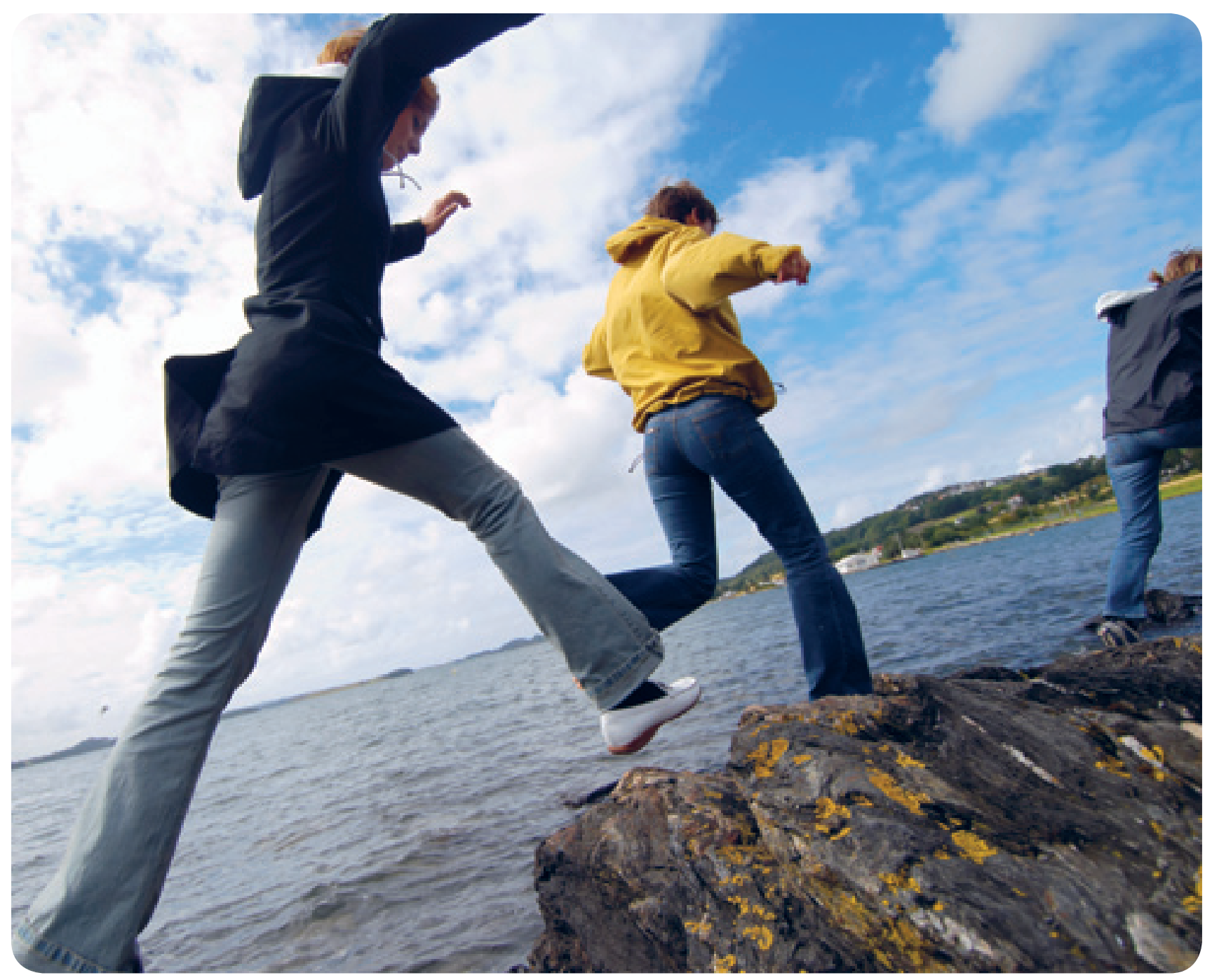

The project "Nutrition, learning and health" attempts to answer the question of what role food and food supplements play in children's health and learning. The initial results from the project have recently been cited in a Nordic report: "Diet in school and pre-school and its significance for health and learning"

The report systematically reviews the research literature on the relationship between nutrition, learning and health. The report finds that the diet regimes in schools and pre-schools in the various Nordic countries are very different and designed with different goals.

There is, however, a sufficient amount of research findings of high quality to give an answer to the effect in certain areas of serving food in schools and pre-schools. However, the report also points to some areas where existing knowledge is poorly developed and urges research studying the effect of the meal and not just the food.
NordForsk was asked to implement phase 2 of "Nutrition, learning and health". Therefore a call has been sent out in 2012 with an allocation of 4 million NOK over 2 years. The aim of this call for proposals is to fund interdisciplinary research projects to study the conditions around meals in schools and pre-schools and their impact on learning in the Nordic countries.

Special emphasis should be given to topics such as:

- Different models for organising meals in schools and their impact on learning, e.g. learning capacity throughout the school day.

- The connection between homes and schools in respect of the type of meals and food served in schools in Nordic societies.

- The link between meals in schools and questions regarding exercise and sports, physical health, and pupils' notions of their appearance and bodies.

(http://www.norden.org/no/

publikasjoner/publikasjoner/2011-534). 


\title{
Nordic centre of excellence - nutrition
}

Facts

The Nordic Centre of Excellence - Nutrition consists of 3 different 5-year research projects running until the end of 2012. The projects are being financed by NordForsk and carried out with the help of close cooperation between research groups from the five Nordic countries. The 3 projects are entitled HELGA, MitoHealth and SYSDIET.

\section{HELGA - Wholegrain prevents disease}

\author{
Wholegrain products are known as a traditional part of \\ the Nordic diet. These dietary traditions combined with \\ multiyear scientific expertise within nutrition and food \\ research in the Nordic region are the starting point for \\ HELGA.
}

The main goal of the HELGA project is to garner more knowledge about the health effects of wholegrain products. In the Nordic countries the population consumes a large and varied amount of wholegrain products - Norwegians, for example, eat a lot of wholegrain wheat, whereas Danes prefer wholegrain rye. It is wholegrain that is thought to play a role in the prevention of several chronic diseases such as type 2 diabetes, cardiovascular diseases and some types of cancer. This connection is examined more closely in the HELGA project, where interdisciplinary research and cooperation between Nordic research institutes can contribute unique knowledge in the area. In the HELGA project the background for many of the research projects is the "HELGA cohort", consisting of a population group of 120,000 Danes, Norwegians and Swedes, who have been monitored for over 11 years. Of these 120,000 persons many have subsequently been diagnosed with an illness - for example almost 1200 have contracted colon cancer. For these persons there is comprehensive information about their wholegrain intake, which can inform us about what role wholegrain plays as regards the risk of contracting a number of diseases.

Wholegrain is characterised as products that include all 3 main components of the grain: the germ, albumen and husk. Albumen primarily contains protein and carbohydrates. The husk and germ of the grain, on the other hand, are rich in dietary fibre, vitamins and minerals and a number of other beneficial substances. In terms of cancers, the HELGA project has so far produced scientific results concerning wholegrain intake and fibre intake in relation to breast cancer and colon cancer. Whilst wholegrain does not appear to protect against breast cancer, the studies indicate that wholegrain nonetheless has a protective effect as regards colon cancer (the third most common form of cancer) - and especially for men. The studies also show that in particular fibre in wholegrain products has a beneficial effect in terms of colon cancer compared with other foods that also contain fibre (fruit, vegetables, po-
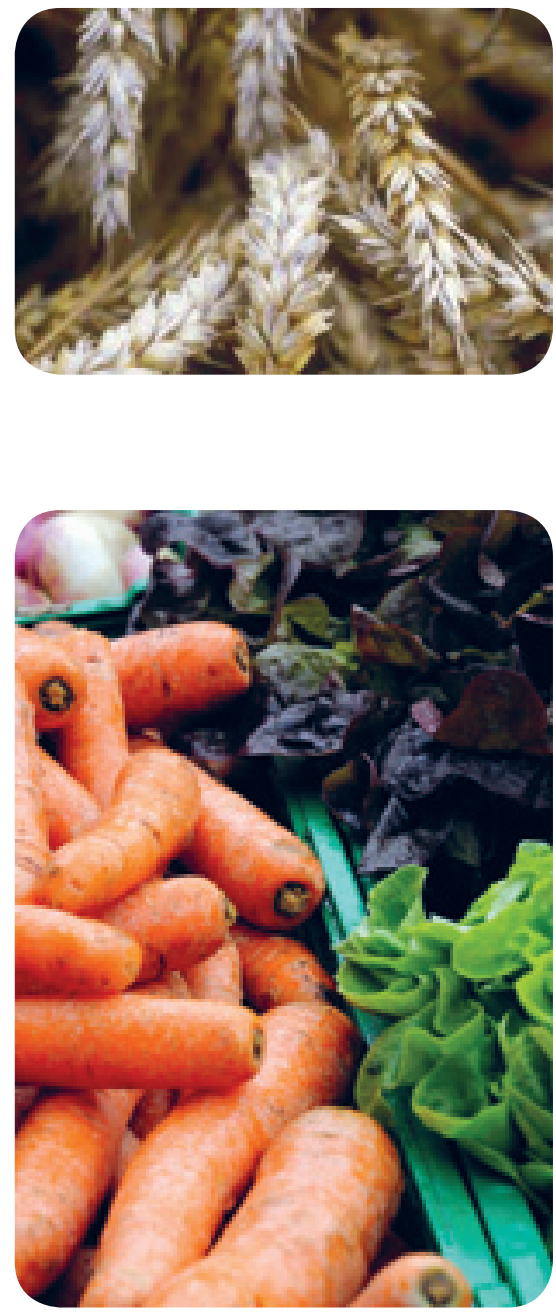

tatoes). Moreover there are also several projects underway studying whether wholegrain has a preventive effect as regards type 2 diabetes and cardiovascular diseases.

\section{Rye may have special properties} Rye occupies a special place in the Nordic food culture. A lot of wholegrain rye is eaten, especially in Denmark and Finland. In some minor studies some highly interesting results have emerged; rye appears to have an especially beneficial effect on the regulation of glucose/ insulin. Imbalance in glucose/insulin regulation is significant for a number of diseases, e.g. type 2 diabetes and prostate cancer. It also appears that wholegrain rye can reduce the blood concentration of prostate specific antigen (PSA) in prostate cancer patients.

The HELGA project also studies what role bread plays in the Nordic food culture. 
Researchers have for example studied the historical context of the status of bread and wholegrain in the food culture over the ages, where specific regions in the Nordic countries are selected. Furthermore anthropology is incorporated in the study in question, where wholegrain rye and physical activity are studied in prostate cancer patients. A central part of the HELGA project is also to combine several different research disciplines, e.g. also nutrition and food research with social research.
Important research findings on the way

The main research findings from the HELGA project are still in the pipeline and are expected to be published in the course of the next few years. Amongst other things it is hoped that the study findings can help to provide answers to the preventive effective of wholegrain on colon cancer and type 2 diabetes. Moreover results are also expected from a major study which may well prove or disprove the extent to which acrylamide (a substance produced especially dur- ing the preparation of starchy foods) increases the risk of breast cancer. The HELGA project has already now had an impact: the study findings have inter alia contributed to the World Cancer Research Fund now thinking that there is sufficient scientific information to prove that fibre prevents colon cancer. Furthermore the HELGA project supports the wholegrain campaign and the new wholegrain recommendations in place in Denmark, Norway and Sweden.

\section{MitoHealth - Health effect of food from marine resources}

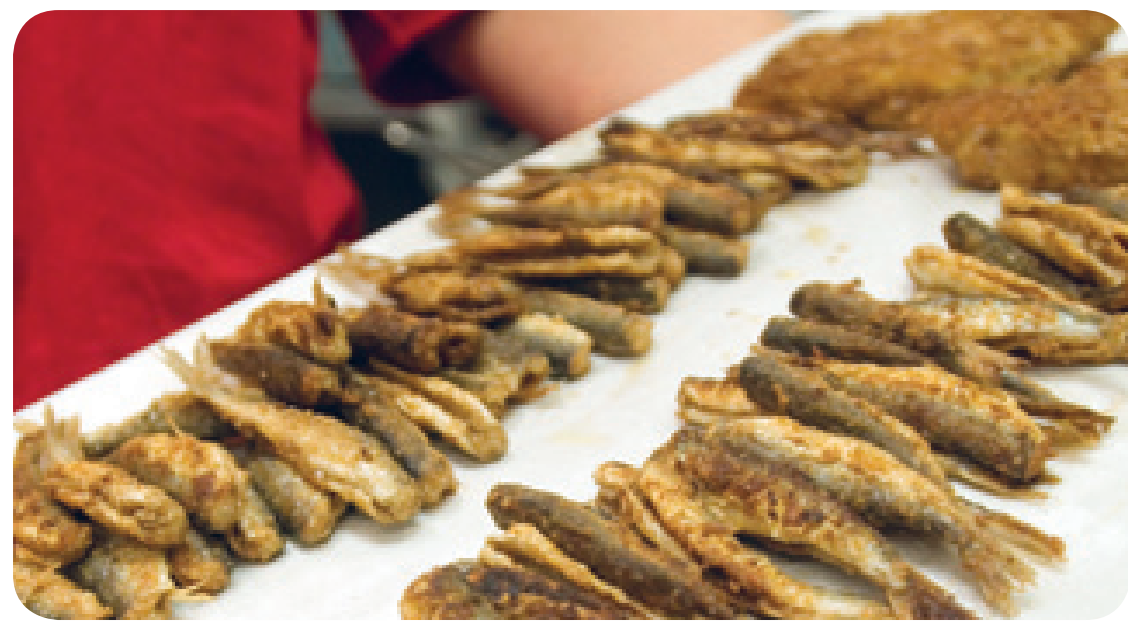

The aim of MitoHealth is to investigate the health effect of food from marine resources. The beneficial effects of seafood are well recognised, but there are still unanswered questions which need to be studied in more detail.

- Which components in marine raw material are most beneficial for human health?

- Where can bioactive components besides those found in fish oil be identified in marine organisms?

- Why and how will these affect human health

To answer these questions, several topics are being studied. Animal models are being used to evaluate the bioactive components in marine resources and to study how they may regulate intestinal function and $a b$ - sorption. The importance of mitochondrial function in health and disease is studied further and also the extent to which it may be improved by bioactive components. Studies are also being conducted to identify relevant molecular mechanisms by studying the regulation of genes and the role of specific genes by using genetically modified mice. Epidemiological studies are also a part of this programme to identify markers for mitochondrial function and to investigate the relationship between diet and disease development.
Studies of marine components in rodents include both oils and peptides processed from fish protein to identify similarities and differences in their mode of action. The studies have shown that it is possible to differentiate between fish oil and krill oil, and that enzymatic hydrolysis of proteins may result in products with different metabolic effects. It has been shown that marine peptides tend to decrease the feed efficiency, which may be related to effects on intestinal absorption or energy expenditure. Mice experiments have shown that fish oil and krill oil have differential effects on lipid and glucose metabolism. Studies on gene expression indicate that fish oil and krill oil affect genes involved in fat metabolism differently, suggesting that they reduce plasma lipids at least partly via different mechanisms. This can be related to different molecular structures of the lipid molecules in these oils.

A study mapping the complete set of lipid molecules in blood and liver samples are underway.

Some of the studies focus on the roles of mitochondria in cellular fatty acid synthesis. In spite of intensive research, the molecular mechanisms translating the effects of omega-3 fatty acids into changes in gene expression have remained largely enigmas. To get insight into these problems the MitoHealth project uses knockout mice 
deficient in specific mitochondrial genes so as to investigate the molecular actions of omega- 3 fatty acids as well as other lipid components of fish oil at the interplay between lipid and carbohydrate metabolism.

Other studies investigate how nutrition signalling modifies the action of so-called transcription factors, which are important for the regulation of gene expression, and have revealed that fat feeding affects how these molecules bind to the DNA molecule.

Epidemiological data from large-scale clinical trials are being used to evaluate new potentially clinically useful markers of mitochondrial function and their prognostic effects. Such data indicate that dietary intake of omega-3 has minor influence on the risk of subse- quent coronary events in patients with stable angina. Reanalysis focusing on subgroups has, however, shown that dietary omega-3 has a protective effect in patients with diabetes. Other studies focus on the relationships between plasma and urinary levels of specific metabolites and their relationship with diabetes and the risk of cardiovascular events.

\section{SYSDIET}

\section{SYSDIET is based on the expertise of 12 partners (14 research groups) from five Nordic countries and aims at a coordinated effort in exploiting nutrigenomics/systems biology tools in human randomised controlled dietary interventions and animal and cell culture studies in order to discover novel mechanisms by which Nordic foods and diets could be modified to promote health and prevent chronic diseases.}

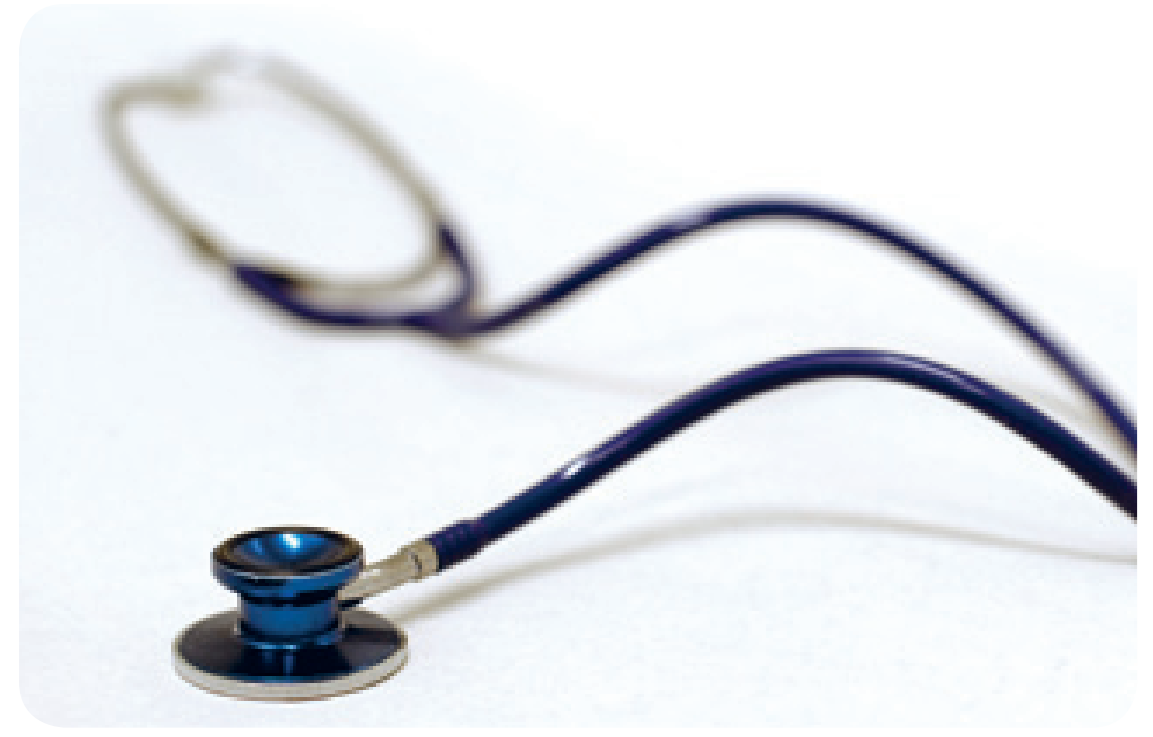

In particular, the focus is on metabolic syndrome, which is the clustering of risk factors associated with abdominal obesity, leading to an increased risk of cardiovascular diseases and type 2 diabetes. The aim is to identify the new biomarkers that are associated with the increased risk of metabolic syndrome by applying modern metabolomics and nutrigenomics tools. The objective is to build a network and infra-structure with a range of expertise to efficiently apply systems biology methodology in nutrition and food science in the Nordic countries. This will strengthen the expertise of partners so that they can carry out high-quality dietary intervention studies and make the Nordic countries more competitive in food science and human nutrition studies.

In metabolomic studies, the goal is to identify metabolites from blood, urine and faeces samples that might be re- lated to the early metabolic disturbances characteristic of metabolic syndrome. To this end, a randomised controlled dietary intervention study on healthy Nordic food has been successfully carried out. Altogether 166 persons completed the intervention at six SYSDIET centres in four Nordic countries. The key foods in the intervention were rapeseed oil, wholegrain cereal products, including rye bread, low-fat milk products, local fruits, roots and berries, and fish. During 2011 the transition occurred from the practical part of the dietary intervention to the centralised sample analyses, data management, interpretation and reporting. The healthy Nordic diet resulted in beneficial changes in serum lipid profile and inflammatory factors favouring its health-promoting properties. The main results are expected to be published soon.

The focus in SYSDIET has also been to improve PhD student training in food and nutrition research in all Nordic countries. A number of courses and laboratory training classes have been organised for doctoral students. In the near future, our aim is to build a permanent Nordic graduate school or network of schools in the field of food and nutrition. SYSDIET also represents an excellent platform for future dietary intervention trials in Nordic countries. Together with other $\mathrm{NCoE}$ programmes in this field our aim is to plan various implementation and communication efforts to enhance knowledge about the principles of healthy Nordic food choices. 


\section{National action plans}

\section{Sweden}

Health developments in Sweden show both positive and negative trends. The most disturbing is the rise in obesity. Today half of all adult Swedes and one child in five are overweight or obese. Some studies indicate that overweight and obesity are not rising further among 10-year-olds, but it is too early to say whether overweight among children has really ceased to increase and whether a reversal is taking place. Obesity increases the risk of other diseases, such as type 2 diabetes and cardiovascular disease. Even though mortality from cardiovascular disease has decreased in Sweden in recent decades, it remains by far the greatest cause of morbidity and death. The WHO considers that better dietary habits, stopping smoking and sufficient physical activity can reduce the risk of overweight/obesity, diabetes, cardiovascular disease and certain cancers.

On behalf of the government, in 2005 the National Food Agency and the Swedish National Institute of Public Health drew up a basis for a national action plan for good dietary habits and increased physical activity. The government has not decided upon an action plan but several proposed activities have nonetheless been carried out at the national level.

\section{Dietary guidelines for children} During 2011 the National Food Agency launched new dietary guidelines for infants and toddlers. Leaflets directed at parents are disseminated free of charge via child health centres. The leaflets are translated into nine languages. Both the benefit and risk assessment report and the benefit and risk management report are published on http://www. slv.se/sv/grupp1/Mat-och-naring/ Kostrad/

This was the first time a special risk management report has been produced, which shows what considerations were made when the advice was put together following a risk-benefit evaluation based on scientific studies.
Dietary guidelines for pregnant and breast-feeding women

The National Food Agency has updated its dietary guidelines for pregnant and breast-feeding women. A new feature is that pregnant and breast-feeding women can also get information and answers to their questions on Facebook and via mobile text messaging. Read more at http://www.slv.se/sv/grupp1/ Mat-och-naring/Kostrad/gravida/

\section{Skills centre for meals in schools} and health and social care In Sweden around 3 million meals are served each day in schools and health and social care. On behalf of the government, the National Food Agency has set up a national skills centre for meals in the public sector. The skills centre will contribute to coordinating and developing the resources and knowledge possessed by various actors so as to reach the vision of all partakers in schools and health and social care enjoying and benefiting from their meals. Read more at http://www.slv.se/ sv/grupp1/Mat-och-naring/Maltider-ivard-skola-omsorg/Nationellt-kompetenscentrum/

\section{Nutritional school meals}

Since 1 July 2011 the Swedish school law has stated that lunch in elementary school shall not only be free of charge but also nutritional. So as to support municipalities and independent schools in meeting this requirement, the National Food Agency and the Swedish National Agency for Education will run an information and education campaign in late 2012 and 2013 on nutritional school food and putting together a school meal. Read more at http://www.slv.se/sv/grupp1/Mat-ochnaring/Maltider-i-vard-skola-omsorg/ Skolmaltider/

\section{Dietary guidelines in care for the elderly}

The National Food Agency has developed dietary guidelines for care for the elderly. The guidelines are directed at elderly persons who receive support with food and meals from their municipality, either at a nursing home or in their own home. The guidelines are divided into four parts and are directed at various target groups with responsibility for meals within care for the elderly, e.g. decision-makers, purchasers, operational managers, dietary managers, kitchen staff and care personnel etc. The dietary guidelines in care for the elderly are based on scientific evidence, including the nutritional requirements and physiology of the elderly, and how the meal environment and treatment affect their eating. The guidelines and evidence can be consulted at http:// www.slv.se/sv/grupp1/Mat-ochnaring/Maltider-i-vard-skola-omsorg/ Maltider-i-aldreomsorgen/

\section{Meals in healthcare}

The National Board of Health and Welfare together with the National Food Agency has put together examples of how healthcare is working to create good meal experiences for its patients. Read more at http://www. socialstyrelsen.se/patientsakerhet/ matochnaringinomhalso-ochsjukvard/ maltidsupplevelser

\section{Study of dietary habits}

A third Swedish national study of adults' (18-80 years) dietary habits has been carried out in cooperation with Statistics Sweden. The data collection, which was carried out over a year, was completed in mid-2011. A total of 5000 persons were asked if they wanted to participate in the study by recording everything they eat and drink over a four-day period using a web-based method and by answering a questionnaire. A thousand of these persons were also asked if they would give a blood and urine sample to study concentrations of environmental toxins and nutrients. The environmental toxin study of dietary habits and blood and urine is being performed jointly with the Swedish Environmental Protection Agency. The processing of the responses began in autumn 2011 and the first results of the study will be published in late spring 2012 . The results of the 


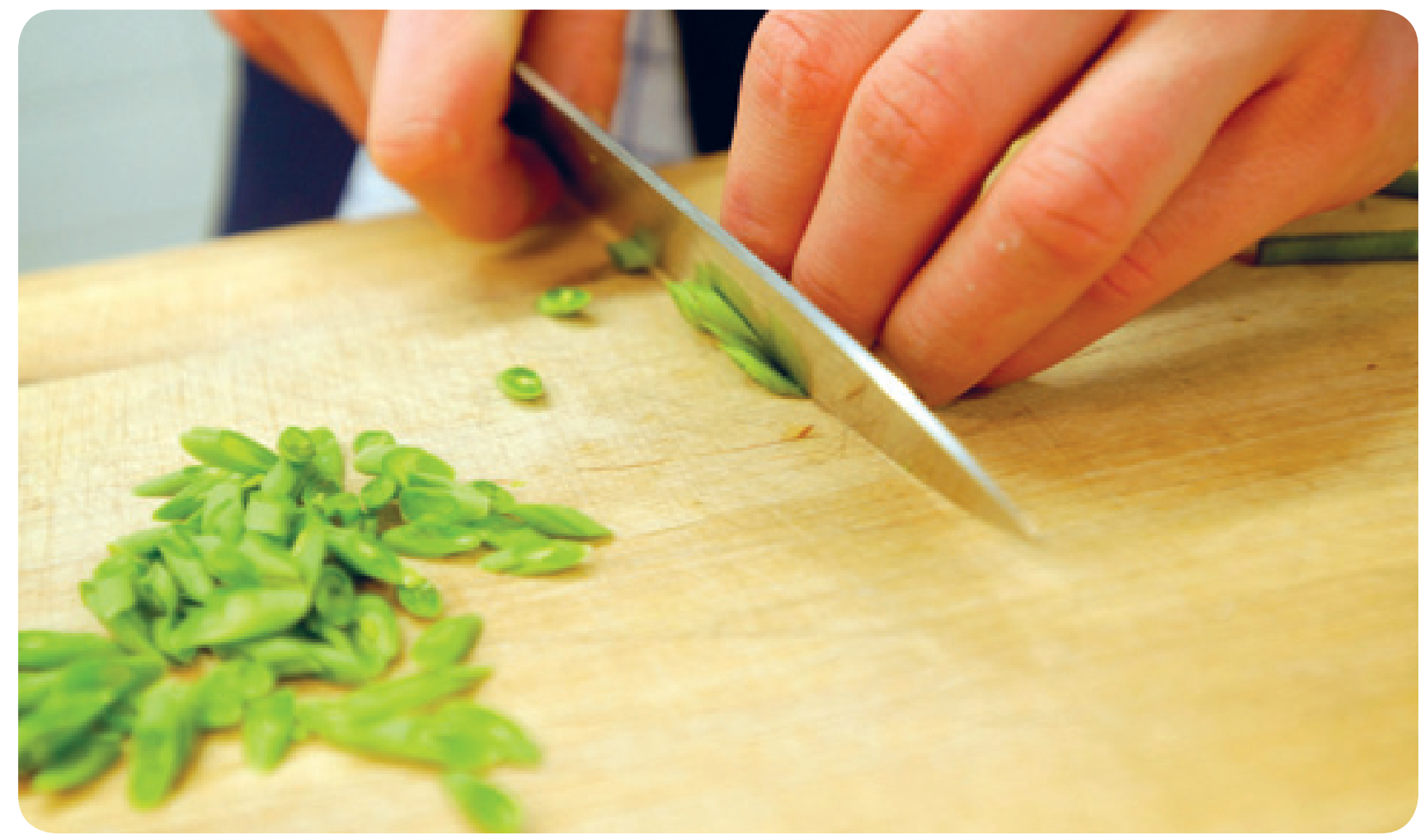

dietary study and the revised Nordic Nutrition Recommendations will provide the basis for a future review of the Swedish dietary guidelines.

\section{Food database}

The National Food Agency's food database contains information on the content of over 50 nutrients in over 2000 foods and dishes. The food database has several applications. It is an important tool when the National Food Agency makes nutritional and dietary recommendations. It is also used in dietary habit studies, to monitor Swedes' dietary habits. It is also used by many external users, both individual users and within universities, municipalities and county councils. The food data can be accessed on the National Food Agency's website and every month around 70,000 searches are made in the database. The Agency analyses about 40 different foods each year to keep the food database up to date. The food database was expanded in 2011 with new analysis values for around 30 fish, fish products and shellfish. There is a link to the database on www.slv.se

\section{Dietary habit check}

The dietary habit check is an aid towards good dietary habits and works both for individual persons and those who want to monitor the dietary habits in a particular group. You can choose between a quick test or recording one or several meals. The quick test gives you an idea of how well you are following the National Food Agency's dietary guidelines and consists of several questions about your dietary habits.

In the other test you record what you eat during a meal, a day or several days - you yourself choose how long to carry on. The more days you record the better the picture you get of your dietary habits. The dietary habit check quick test also includes a project part, which is primarily aimed at municipalities, county councils and associations that want to measure dietary habits in a specific group or evaluate action being taken for good dietary habits. The dietary habit check has been developed in cooperation with the Swedish National Institute of Public Health. The tests are adapted for adults. Test your dietary habits with the Dietary habit check on the National Food Agency's website http://www.slv.se/ sv/grupp1/Mat-och-naring/Kostrad/ Test-matvanekollen/

\section{A healthier Sweden}

On behalf of the government, the National Institute of Public Health organises an awareness week on good dietary habits and physical activity every year. The awareness week is a collaborative project designed to promote good dietary habits and physical activity amongst the public. It is municipalities, county councils/regions, nonprofit organisations and private actors who contribute. Read more at http:// www.fhi.se/Vart-uppdrag/Matvanor/ ettfriskaresverige/ 


\section{Denmark}

The health of the Danes has a high political priority and the government's goal is that free and equal access to health should be ensured. There is great inequality in health and for the individual Dane their health status depends to too great an extent on their income and education. The government point out that prevention is one of the keys to solving the challenges of inequality in health status and living life well. Specifically, the government is in the process of defining national targets for the Danes' health status development 10 years hence and these targets are to be met by prioritising preventive action both nationally and in municipalities. Prioritising preventive action means, inter alia, increasing cigarette duties and duties on beer, wine, sugar, fat and other unhealthy food, launching targeted health action for exposed groups and working on practical targets for preventive action in municipalities. In addition focus is on a number of activities to support healthy food and lifestyle for all. In Denmark the state responsibility in this area is divided into the Danish Veterinary and Food Administration under the Ministry of Food, Agriculture and Fisheries and the National Board of Health under the Ministry of Health and Prevention.

\section{Healthy dietary habits}

The Ministry of Food, Agriculture and Fisheries is working in a focused manner to promote healthy dietary habits in the population by promoting proper food for children and by making it easy to make healthier choices every day. In May 2012 the ministry replaced its 2008 food and meal policy with a new meal policy initiative, "Healthy food and lifestyle - an easier choice for all". A large number of actions since the 2009 progress report support the Nordic action plan.

\section{Proper food for children}

So as to promote proper food for children and young people, the "All About Diet" mobile team assists municipalities in the process from policy formulation to implementation

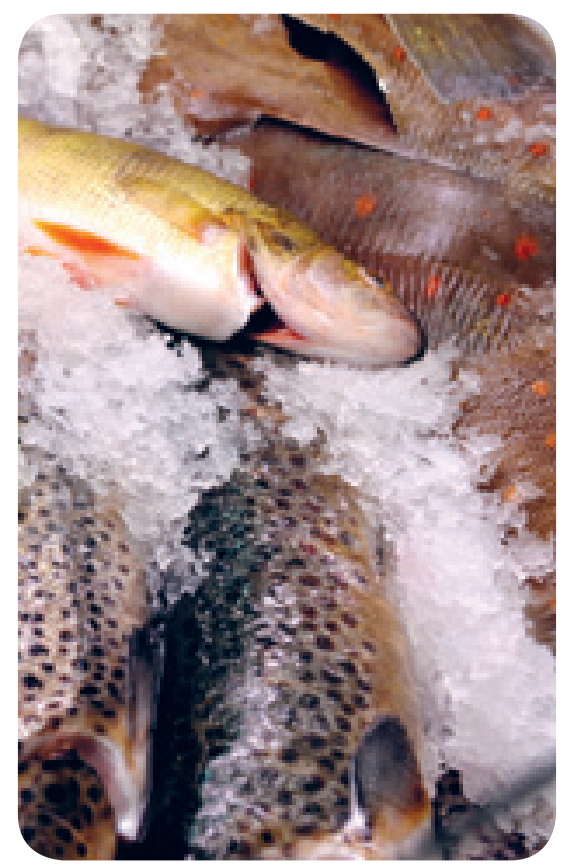

of dietary arrangements, facilitates networks, disseminates best practices and contributes to skills development. Healthier food in sports halls has been a new focus area. Since 2012 the Veterinary and Food Administration has been involved in a 3-year partnership and intervention project 'Healthier food in sporting life' together with a number of stakeholders and municipalities. In spring 2012 the Veterinary and Food Administration published the booklet 'Food in sports halls', which provides inspiration and recipes for sports halls that want to offer their customers a healthier range of products.

\section{The Keyhole}

The Keyhole is a hub for a large number of initiatives designed to make it easy to make healthier choices, both when shopping and when eating out. In April 2012 the Veterinary and Food Administration launched Keyhole-labelled recipes on a new mobile site, where consumers can find recipes which make it easy to make healthier food at home. On 1 February 2012 the Veterinary and Food Administration's new secretariat for 'The Keyhole at Eating Places' opened its doors. 'The Keyhole at Eating Places' is a voluntary labelling scheme targeted at all eating places in Denmark, e.g. canteens, restaurants, course establishments and fast food restaurants, and which gives the establishments the possibility to Keyhole-label entire meals.
Partnerships and campaigns targeted at citizens have proved highly effective.

The public-private partnership "Choose wholegrain first" is continuing to work to increase the accessibility of wholegrain products and disseminate awareness of the beneficial effect of wholegrain. A new partnership is being set up in 2012 focusing on meals rather than individual dietary advice / product groups. This Meal partnership is a broad-based venture between trade associations, health and professional organisations and authorities and is designed to make healthy choices attractive, e.g. by focusing on helping those groups that find it hardest to follow a healthy lifestyle. The focus will be on a holistic approach around the day's meals - small and large.

A Salt partnership is working to achieve a reduction in the population's average salt intake of $3 \mathrm{~g}$ per dag within 3 years. That would take the average intake in the population to 6-7 $\mathrm{g}$ for men and 5-6 $\mathrm{g}$ for women. All food producers and the retail trade are being urged in 2012 to develop products so that the salt content can be brought down within a few years. To provide inspiration, recommended reduction targets are being published in April 2012 for salt content in foodstuffs, which many products will be able to reach before the end of 2013.

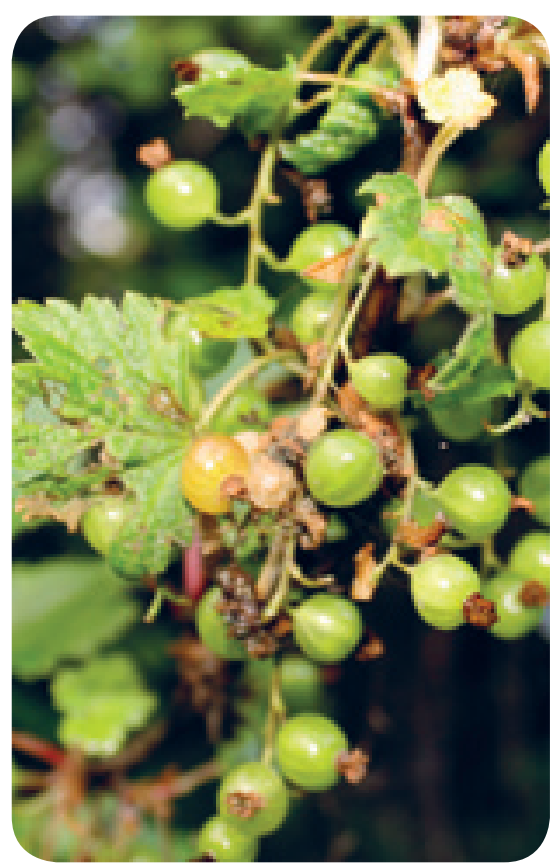




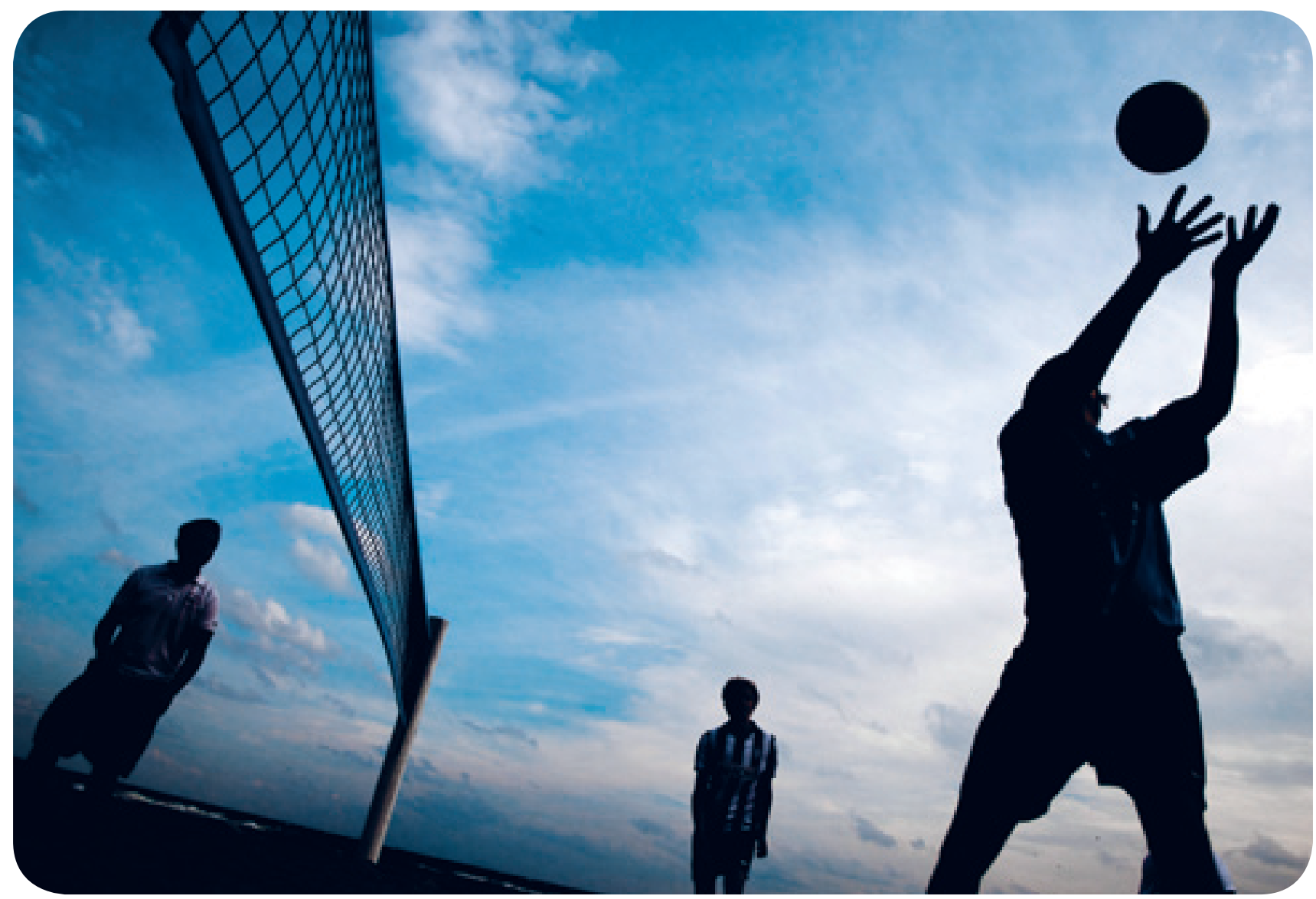

\section{Dietary guidelines}

The official Danish dietary guidelines will be updated in 2012 on the basis of the new NNR. The work is being done in two working groups: nutrition researchers from the DTU National Food Institute are heading a group working on the scientific part, and the Veterinary and Food Administration are heading a group looking into how the new guidelines can be set out in the best possible way and communicated to consumers. Complete transparency in the work is considered important. Progress can be followed at: http://www.altomkost.dk/ Services/Kontakt/netvaerk/Opdatering_af_kostraadene.htm

\section{Physical activity}

Since 2005, the National Board of Health has been carrying out a nationwide campaign on physical activity for children and young people. In spring 2012 the campaign "Get Moving“ will be carried out in weeks 16-18 targeted at children and young people aged 11-15. This year's campaign is all about street activities to reach those who are least physically active, and to tell that physical activity is more than sport and athletics. Four selected municipalities are implementing various actions focusing on structural measures that contribute to more activity in the target group in and around school. See more at www.getmoving.dk

In December 2011 the National Board of Health published a revised edition of "Physical activity" - a handbook on prevention and treatment. The book contains new evidence on physical activity acting as prevention and treatment for 32 different diseases and adjusted recommendations for physical activity. Can be downloaded at www.sst.dk

\section{The National Board of Health's spe-} cial initiatives against overweight In the "Municipal plan against overweight" (Rate adjustment pool 20052008), DKK 73 million is set aside for prevention and treatment of severe overweight among children in vulnerable families, including ethnic groups. The two first part-evaluations of the pool came out in 2009 and 2011, whilst both the third part-evaluation and the overall evaluation are expected in mid2012. They are available on www.sst.dk
In "Weight loss and weight maintenance in severely overweight adults" (Rate adjustment pool 2007-10), DKK 57.5 million is earmarked for targeted action for severely overweight adults. The aim is to develop support functions to increase competence and motivation to lose weight and maintain weight, and to increase competence among municipal/ regional employees supporting severely overweight adults. Weight stop advisor schemes have been set up with weight stop advisors in over 40 municipalities/ regions and key person schemes at 12 workplaces to pay particular attention to overweight in co-workers. The pool has helped to develop a training scheme for weight stop advisors. All the teaching material was made available on www.sst.dk/VAEGTSTOP in 2011. The mid-term review was released in January 2011, and the final evaluation is expected in early 2013 . See more on www.sst.dk

In “Children's well-being in vulnerable families with overweight or other health risks" (Rate adjustment pool 2010-13), DKK 46 million is earmarked for interdisciplinary action for children in vulner- 


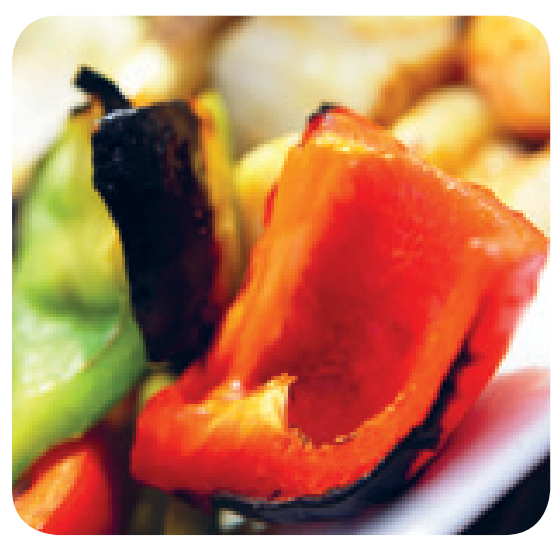

able families. The resources are being disbursed to 14 municipalities to try out various model projects to develop the quality of municipal action on children's well-being. The aim is, through early intervention and by focusing on interdisciplinary cooperation, to try out methods and models which particularly involve and recognise parents and their importance for children's well-being and health. See more on www.sst.dk.

In 2007 and 2009, the National Board of Health and the Danish College of General Practitioners developed clinical guidelines to support doctors and practicing personnel in working with overweight with both pre-school children and adults. In 2012 corresponding guidelines were developed for the municipal health service to detect overweight and intervene early with school children. The guidelines are available on www.sst.dk.

Both bodies carry out ongoing studies within their own areas so as to track developments closely. For example, in March 2011 the National Board of Health and the Ministry of the Interior and Health jointly launched the results of a nationwide study of the Danes' health, 'How are you?'. Almost 180,000 Danes answered questions about their health, well-being and illnesses, including diet, physical activity and weight. See more in the report 'The national health profile 2010 How are you?' or in the interactive database at www.sundhedsprofilen2010. $\mathrm{dk}$. The National Board of Health has established a Children's database. Data reporting became obligatory for municipalities in December 2011,

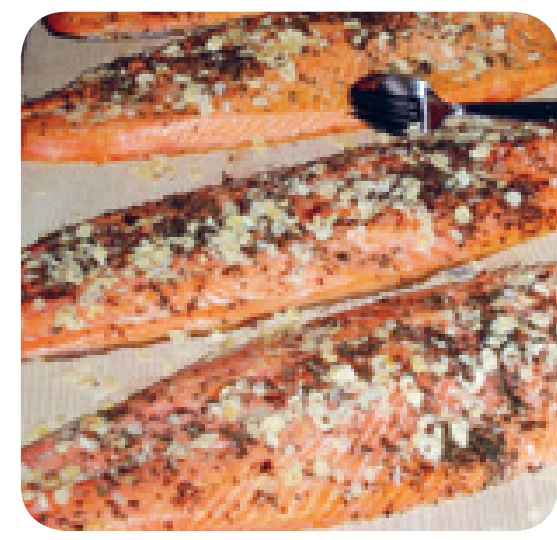

and for the time being is voluntary for practicing physicians. The reporting includes data on children's height, weight and passive smoking at birth and breast-feeding. (Is envisaged to be expanded later to include further indicators of children's health). Data extracts can be made via www.sst. dk. Go to Indberetning og statistik -> Sundhedsdata -> Kommunale sundhedsindikatorer and here select the lowest link under Børnesundhed: Børnesundhed, udgifter og effekt, after indikator og område. Here overweight children aged 6-16 are indicated.

http://www.sst.dk/Indberetning\%20 og\%20statistik/Sundhedsdata/ Kommunale\%20Sundhedsindikatorer. aspx on www.sundhedsprofilen 2010 . $\mathrm{dk}$.

\section{On health promotion at the work- place}

In 2009 the National Board of Health published "Health and well-being at the workplace" to inspire companies to work systematically to promote their employees' health and wellbeing" The publication presents a new 5-step model for how a company can elevate health-promotion work from the staff benefit level to a strategic tool. The publication was sent to 20,000 companies and is directed at company managers, $\mathrm{HR}$ directors and consultants as well as shop stewards and safety representatives. As a follow-up to this and the Danish Healthy Cities Network's publication "9 steps to health and well-being at the workplace - the good municipal model" five regional implementation meetings were held in 2010. See more on www.sst.dk.

\section{Finland}

In 2008 "the Government Resolution on development guidelines for health-enhancing physical activity and nutrition" was published (www.stm.fi/ publikationer ). The National Nutrition Council and the National Council for Health Promoting Physical Activity developed an implementing programme for these guidelines for the years 2008-2011.

The National Nutrition Council has published the following recommendations:

- Beverages in nutrition, 2008

- Recommendations for school meals, 2008

- Nutrition recommendations for the elderly, for hospitals, care centres, nursing homes and rehabilitation institutes, 2010

- Recommendations for food catering establishments, 2010

- Nutrition therapy, 2010

- Recommendations for student food catering establishments, 2011

The task force appointed by the Finnish National Nutrition Council has finalised its report on the development of the national food analysis programme.

Even though vitamin D status has been improved in Finland in recent years, the average intake is still below the recommended level. The National Institute for Health and Welfare, the National Nutrition Council and the Finnish Paediatric Society issued their new recommendations on vitamin $D$ supplements for children, pregnant and breast-feeding women (http:// www.ravitsemusneuvottelukunta. fi/portal/se/meddelanden_och_ stallningstaganden/).

In Finland, vitamin D has been added to liquid milk products and vegetable fat spreads since 2003. All fortification is voluntary. In 2010 the National Nutrition Council doubled its recommendations and the current recommendations are the following: liquid milk products $1 \mu \mathrm{g} / 100 \mathrm{ml}$ and fat spreads 20 $\mu \mathrm{g} / 100 \mathrm{~g}$. Organic liquid milk products are not fortified with vitamin D. 
In the new Finnish healthcare law, health promotion, e.g. in maternal and child health care centres was enhanced.

The working group on sugar taxation starting working in 2012 and will explore what type of sugar tax would best meet central government's fiscal targets and would at the same time promote healthy nutrition. In Finland sweets, ice cream and soft drinks are currently subject to increased tax.

The following reports on child and adolescent nutrition have been published:

- Kyttälä et al. The Diet of Finnish Preschoolers. Publications of the National Public Health Institute, B32/2008, 154 pages. (In Finnish, abstract in Swedish and English)

- Hoppu et al. Nutrition and wellbeing of secondary school pupils. Situation at baseline and results of the intervention study during academic year 2007-2008. Publications of the National Public Health Institute, B30/2008, 283 pages. (In Finnish, abstract in Swedish and English)

A special issue of Public Health Nutrition, "Nutrition and Health in Finland" (2010;13(6A)), has been published, including 14 articles about nutrition policy, monitoring, dietary methods, the diet of different population groups etc. The National Findiet 2012 Survey, the national dietary survey of adults, was performed in 2012 and will be reported in 2013.

The iodine status in Finland has been evaluated. The mean iodine intake was found to be adequate, but depends very much on the consumption of milk products, and thus a substantial proportion of the population may have a sub-optimal intake. The following recommendations were given: all table salt should be iodised; the salt used in food catering services and in ready-toeat food should be iodised; the iodine status of subjects at risk (e.g. children, pregnant women) should be monitored systematically.

\section{Dorway}

Enhanced action for public health

Through the National health and care plan (2011-2015) the government has set the political course for health and care services and public health work for the next four years. The government's starting point is, inter alia, that it is a public responsibility to promote health and prevent illness, and that things should be arranged so that it is easy to make healthy choices when it comes to both diet and physical activity.

One of the goals in the Coordination Reform is to promote health and prevent illness more than today and to level out social health disparities. The Act on Public Health Work which came into force on 1 January 2012 places a cross-sectoral public health responsibility on municipalities, counties and state authorities. The Act obliges municipalities and counties to have an overview of the health situation and relevant factors, including nutrition and physical activity, to initiate measures to monitor the challenges and to anchor this in their planning system. http://www.lovdata.no/ cgi-wift/wiftldles?doc=/app/gratis/ www/docroot/all/nl-20110624-029. html\&emne=folkehelselov $*$

One of the measures in the follow-up of the Coordination Reform is to focus on developing and promoting healthy living centres in municipalities. This is preventive health care for persons who need to alter their health behaviour, physical activity and nutrition. The basic offering is the healthy life recipe, covering a period with structured follow-up. Doctors, other health personnel and employment offices can issue the recipe. As of early 2012 there are healthy life centres in $1 / 3$ of municipalities. http://helsenorge.no/ Helsetjenester/Sider/Frisklivssentral. aspx

\section{Physical activity}

A nationwide selection of objectively registered physical activity shows that only $20 \%$ of the adult population meet the recommendation of an average of
30 minutes' moderate physical activity. http://www.helsedirektoratet.no/ publikasjoner/fysisk-aktivitet-blantvoksne-og-eldre/Sider/default.aspx Physical activity registered among children and young people shows that a greater proportion of time is being spent on inactivity and that, comparing the data for 2005-2006 with the 2011 study, the proportion who meet the recommendations is declining. Activity registered with activity goals shows that $70 \%$ of the waking hours of 15 -year-old Norwegians are spent sitting still.

An evaluation of the Action plan for physical activity (2005-2009) shows that the plan has put physical activity on the agenda and brought across the importance of physical activity in a public health perspective. The plan has contributed to an enhanced knowledge base and increased cooperation between and within several sectors. At the same time clearer priorities, more robust means, more resources, targeted measures, enhanced coordination and a sharper focus are called for. It is recommended that the work is followed up and that cost and administrative efficiency requirements are made. http://vista-analyse.no/no/ publications/samspill_uten_retning_ og_midler_hvem_skal_aktivere_ hvem_evaluering_av_handl/

Physical activity is being prioritised in several other sectors, e.g. through the new strategy of the Norwegian Public Roads Administration for pedestrians and a revision of the cycling strategy. The Norwegian Directorate for Nature Management is working on a community strategy and the Ministry of Education and Research has added two extra weekly hours to free physical activity in classes 5 and 7. In spring 2012 the Ministry of Education and Research will submit a new white paper on sport.

Socio-economic calculations have been carried out which show that if 10,000 residents in a municipality walk 10-15 minutes extra every day, this will lead to an annual welfare 


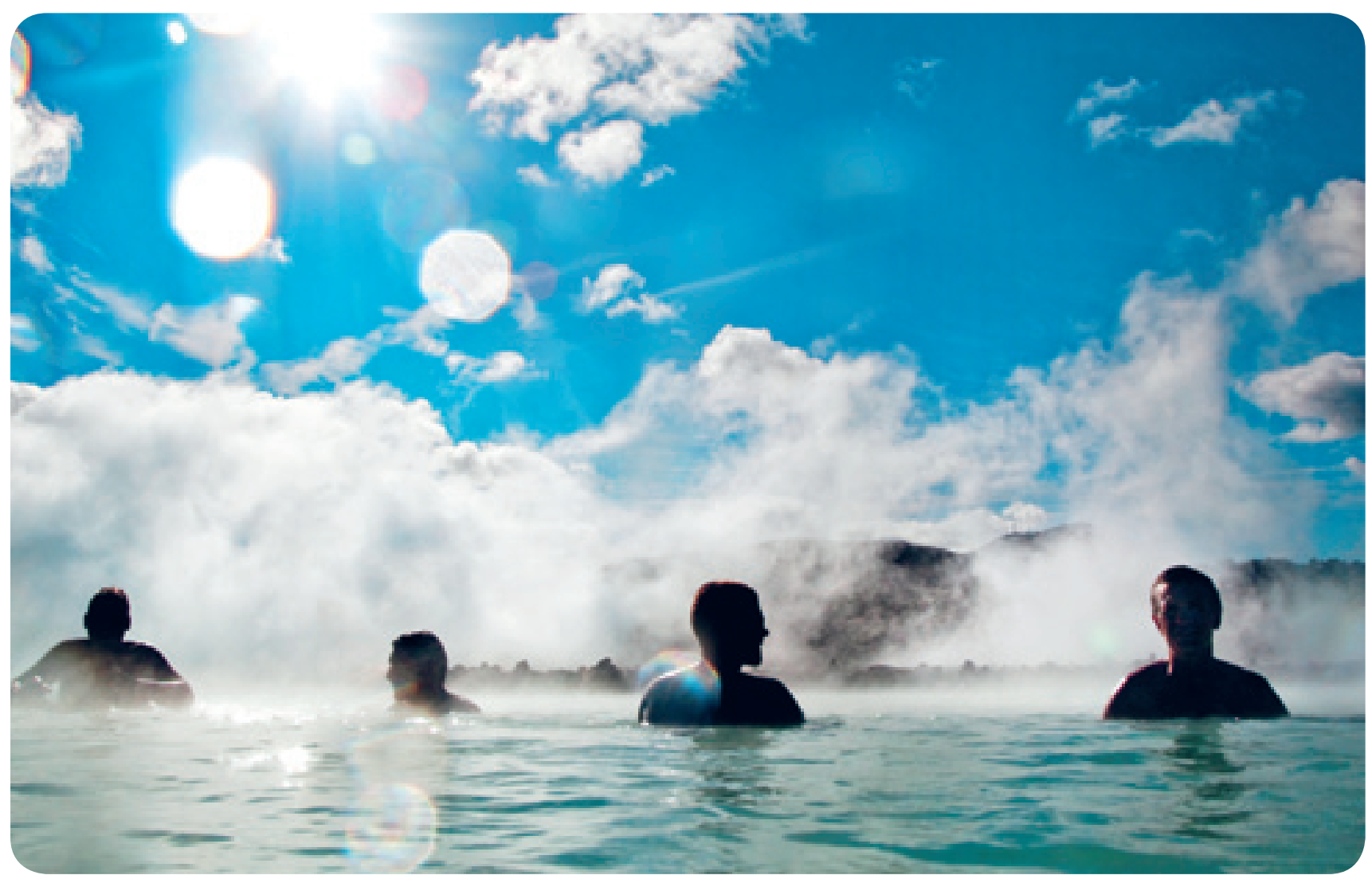

gain of 500 quality-adjusted life years (QALY). In Norway this is valued at NOK 250 million a year.

\section{Healthy dietary habits}

Together with other sectors, the Norwegian Directorate of Health has worked on following up the government's Action plan for better diet in the population (2007-2011). The plan includes quantitative targets for changes in the intake of key foods in line with the Nordic action plant. An expert group from the WHO will review the dietary work in Norway, and issue recommendations for further work. Some important initiatives that have been worked on since 2009 are discussed here.

In January 2011 the Directorate of Health launched new national dietary guidelines based on the report "Dietary guidelines to promote public health and prevent chronic diseases - Methodology and scientific knowledge base", published by the Norwegian National Nutrition Council. The dietary guidelines are based on a thorough knowledge summary of international research into the connection between food and chronic diseases. The report has received considerable attention in the media and has been well received. International fora such as the WHO have shown interest in the report, which is being translated into English.

http://helsedirektoratet.no/publikasjoner/kostrad-for-a-fremme-folkehelsen-og-forebygge-kroniske-sykdommer/ Sider/default.aspx Together with the Keyhole, the new dietary guidelines form the basis for communication on healthy diet in the population.

The Directorate of Health and the Norwegian Food Safety Authority are working together on implementation of the Keyhole. Three consumer-oriented mass media campaigns have been carried out since 2009. Good dialogue with suppliers and the trade on implementation has given a big boost in marketing of the label. $98 \%$ of the population over 18 years know the label scheme and 1 in 2 say that the Keyhole makes it easier to make healthier choices.

Nursery schools and schools are central arenas in the municipalities' public health work. To increase awareness of seafood's nutritional benefits and give children and young people positive taste experiences, the project "Fiskesprell" has been implemented in all counties in the country since 2008 . The project includes training of staff in nursery schools, schools and out-ofhours childcare, material and financial support for raw materials. It is a project between the Ministry of Fisheries and Coastal Affairs, the Ministry of Health and Care Services and the fishing industry. A nursery school survey in 2011 shows that $1 / 3$ of the country's nursery schools have participated in courses and that knowledge and skills from the courses are being used in practice.

The authorities are studying the need for tighter regulation of the marketing of unhealthy food and drinks to children in Norway.

As part of the work on overweight, the Directorate of Health has issued National professional guidelines for prevention and treatment of overweight among both adults and children, and has developed an implementation plan. "GOOD FOOD for better health courses" has been developed for use in the healthy living centres. http://helsedirektoratet.no/folkehelse/frisklivssentraler/bra-mat-kurs/Sider/default.aspx 
$\square$

Iceland

In the Icelandic government's efforts to promote a healthier lifestyle amongst the Icelandic public, i.e. with respect to a healthier diet and increased physical activity, a particular focus has been placed on children and young people, by creating supportive environments that make healthier choices easier. Indeed, as schools play an important role in promoting early healthy habits among children and young people, a particular emphasis has been placed on them.

\section{Health promotion in schools}

The Directorate of Health (which merged with the Public Health Institute of Iceland on 1 May 2011) aims to promote healthy habits among children and young people through various channels, e.g. through a holistic healthpromoting approach within primary (aged 6-15) and secondary (aged 16-20) schools. Almost all secondary schools in Iceland (31 out of 32) and 43 primary schools (out of 175 ) now participate in the project. A health-promoting pre-school project is currently under development. These projects are implemented around four major focus areas: nutrition, physical activity, mental health and lifestyle (which deals with e.g. alcohol, tobacco and substance use). Through this initiative, the Directorate has shaped guidelines for school canteens, educational material promoting both nutrition and physical activity, and collaboration with various relevant agents in the community.

The Directorate of Health, in collaboration with Centre of Child Health Services (within the primary healthcare system), has developed teaching material intended for school nurses to use during health education among pupils aged 6-16. Furthermore, this collaboration between the Directorate and the Centre of Child Health Services resulted in the launch of an educational website: http://www.6h.is.

\section{Physical Activity on Prescription} Physical Activity on Prescription (Hreyfisedill) is a pilot project currently being run within the Icelandic primary healthcare system. The project is based on a similar idea that has now been well established within the Swedish healthcare system, where licensed medical personnel can issue patients with a prescription for physical activity. Hreyfitorg (www.hreyfitorg.is) is an interactive website (set to launch in the spring of 2012) which aims to provide information about the various types of physical activity options being offered at any given time in the Reykjavik area. The project has been developed and funded by the Directorate of Health in collaboration with other stakeholders. It serves as one of the tools facilitating the further development of the Physical Activity on Prescription programme.

\section{National dietary survey}

A national dietary survey among adults was carried out in 2011-2012. The main findings are generally positive in comparison to the observed dietary habits reported back in 2002. The mean consumption of saturated fat, sugar and salt has decreased although saturated fat and salt are still too high in the diet. Consumption of fruits, vegetables and wholegrain bread has increased but is still lower than recommended. Finally, a positive finding revealed that consumption of sugared soft drinks has decreased by $30 \%$ since 2002.

\section{Law and regulation}

The Icelandic parliament (Althingi) has taken a positive stance on the Keyhole, the Nordic nutrition label, in the form of a parliamentary resolution. A legislative bill was recently passed by the Althingi, thereby incorporating the necessary legal provisions to facilitate use of the Keyhole in Iceland. Several producers have shown interest in using the symbol on their products and in fact some producers have already put the label on their products. In August 2011 an Icelandic regulation came into effect that set a maximum level on the content of industrially produced trans-fatty acids in processed foods. The regulation is in line with the Danish regulation. The national dietary survey carried out in 2011-2012 showed that the intake of trans-fatty acids in Iceland has been substantially reduced.

\section{Food business operators}

Collaboration has been established with various parties within the private sector, e.g. the Federation of Icelandic Industries, in order to decrease the salt content of bread and to increase the availability of wholegrain products. The milk industry has been encouraged to fortify milk and milk products with vitamin $D$ and a fortified low fat milk product is already on the market. Collaboration with Icelandic vegetable farmers has been established to increase the consumption of vegetables by children and young people. 


\title{
norden
}

\author{
Nordic Council of Ministers
}

\author{
Ved Stranden 18 \\ DK 1061 Copenhagen K \\ Denmark
}

www.norden.org

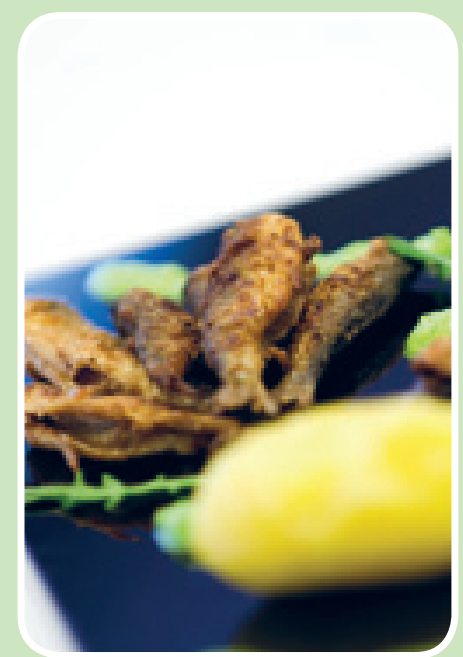

ISBN 978-92-893-2359-8

DOI 10.6027/ANP2012-728

ANP 2012:728

(c) Nordic Council of Ministers

Layout: Nordisk Ministerråd/Erling Lynder Photos: Karin Beate Nøsterud; Svetlana Kolbaneva; Johannes Jansson; Sigurður Ólafsson; S.Sigbjørnsen; Pål Espen Olsen; Magnus Fröderberg; norden.org Print: Rosendahls-Schultz Grafisk A/S, Albertslund

Printed in Denmark

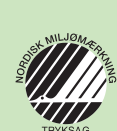

\section{Nordic co-operation}

Nordic co-operation is one of the world's most extensive forms of regional collaboration, involving Denmark, Finland, Iceland, Norway, Sweden, and the Faroe Islands, Greenland, and Åland.

Nordic co-operation has firm traditions in politics, the economy, and culture. It plays an important role in European and international collaboration, and aims at creating a strong Nordic community in a strong Europe.

Nordic co-operation seeks to safeguard Nordic and regional interests and principles in the global community. Common Nordic values help the region solidify its position as one of the world's most innovative and competitive. 